\title{
Ameliyathane Dışı Anestezi Deneyimlerimiz
}

\section{Our Non-operating Room Anesthesia Experiences}

Gülçin Hacıbeyoğlu ${ }^{1}$,

Şule Arıcan ${ }^{1}$,

Sema Tuncer Uzun ${ }^{1}$

Aybars Tavlan ${ }^{1}$

${ }^{1}$ Necmettin Erbakan Üniversitesi Meram Tıp Fakültesi Anesteziyoloji ve Reanimasyon Anabilim Dalı, Konya, Türkiye

Geliş Tarihi/Received: 13 Temmuz 2018 Kabul Tarihi/Accepted: 05 Kasım 2018

Yazışma Adresi: Gülçin Hacıbeyoğlu, Necmettin Erbakan Üniversitesi Meram Tıp Fakültesi Anesteziyoloji ve Reanimasyon Anabilim Dalı, Konya, Türkiye e-posta: drgulcin81@gmail.com

\section{ORCID}

Gülçin Hacıbeyoğlu

https://orcid.org/0000-0002-9438-3414

\begin{abstract}
Öz
Amaç: Bu çalışmada ameliyathane dışı anestezi deneyimlerimizi ve sonuçlarını tartışmayı amaçladık. Hastalar ve Yöntem: Mayıs 2017-Aralık 2017 tarihleri arasında tanı ve tedavi amacıyla ameliyathane dışında sedo-analjezi uygulaması yapılan 18 yaş üstü olguların anestezi kayıtları retrospektif olarak tarandı. Kayıtlar; demografik veriler, uygulanan işlem, işlemin süresi, sedasyon derecesi, kullanılan ilaçlar, gelişen minör ve major komplikasyonlar, kronik obstrüktif akciğer hastalığı öyküsü ve yoğunbakım intiyacı açısından incelendi. Komplikasyonlar ile demografik veriler ve kategorik değișkenler arasındaki ilişkiler analiz edildi.

Bulgular: Toplam 2562 hastaya sedo-analjezi uygulandı. Bu olguların 1428 (\%55.7)'i kadın, 1134 (\%44.3)'ü erkek idi. Yas ortalaması 53.08 16.55 idi. Olguların 268 (\%10.5)'i ASA I, 1683 (\%65.7)'ü ASA II, 598 (\%23.3)'i ASA III, 13 (\%0.5)'ü ASA IV idi. 519 (\%20.3) hastaya minimal sedasyon, 1541 (\%60.1) hastaya orta derecede sedasyon, $502(\% 19.6)$ hastaya derin sedasyon uygulandı. En uzun işlem süresi endoskopik retrograd kolanjiopankreatografide $28.7 \pm 16.3 \mathrm{dk}$, en kısa işlem süresi üst gastrointestinal endoskopide $10.3 \pm 3.1 \mathrm{dk}$ olarak tespit edildi. En fazla uygulanan işlem \%31 ile kolonoskopi idi. En çok kullanılan ilaç kombinasyonu $1231(\% 48)$ hastaya uygulanan midazolam+propofol+fentanil kombinasyonu idi. 148 (\%5.76) hastada minör komplikasyon, 10 (\%0.37) hastada major komplikasyon geliști. Toplam 15 $(\% 0.58)$ hasta prosedür sonrası yoğunbakıma devredildi. Desatürasyon; ASA III ve üzeri hastalarda,15 dakikadan uzun süren işlemlerde, 65 yaş üstü hastalarda ve kronik obstrüktif akciğer hastalığı varlığında istatistiksel olarak anlamlı oranda yüksekti. Işlem sonrası yoğunbakım ihtiyacı da bu hasta gruplarında anlamlı oranda yüksekti.

Sonuç: Ameliyathane dışı anestezi uygulamalarının sıklığı giderek artmaktadır. Bu uygulamalar taşıdığı riskler açısından ameliyathanedeki anestezi uygulamalarıyla benzerdir. Hasta güvenliğinin artırılması ve komplikasyonların azaltılması için işlem öncesi ayrıntılı bir değerlendirme yapılması, uygun fiziksel şartlarda doğru bir monitörize anestezi bakımı sağlanması ve ekipler arasında sağlıklı bir iletişim kurulması önemlidir.
\end{abstract}

Anahtar Kelimeler: Ameliyathane dışı anestezi, sedasyon, monitörizasyon, komplikasyon

\section{Abstract}

Aim: In this study, we aimed to discuss our experience and results of non-operating room anesthesia.

Patients and Methods: Anesthesia records of patients older than 18 years who underwent sedoanalgesia outside the operating room for diagnosis and treatment between May 2017 and December 2017 were retrospectively screened. The records were examined in terms of demographic data, applied procedure, duration of the procedure, sedation grade, medications used, developing minor and major complications, chronic obstructive pulmonary disease story and intensive care need. Relationships between complications with demographic data and categorical variables were analyzed.

Results: Totally 2562 patients underwent sedo-analgesia. $1428(55.7 \%)$ of these cases were female and $1134(44.3 \%)$ of them were male. The average age of patients was $53.08 \pm 16.55 .268(10.5 \%)$ of the cases were ASA I, $1683(65.7 \%)$ were ASA II, 598 (23.3\%) were ASA III and $13(0.5 \%)$ were ASA IV. 519 $(20.3 \%)$ patients were minimally sedated, $1541(60.1 \%)$ were moderate sedated and $502(19.6 \%)$ deep sedated. The longest procedure time in endoscopic retrograde cholangiopancreatography was $28.7 \pm 16.3$ $\mathrm{min}$, and the shortest procedure time in endoscopy was $10.3 \pm 3.1 \mathrm{~min}$. The most commonly performed procedure was colonoscopy with $31 \%$. The most commonly used drug combination was midazolam + propofol + fentanyl applied to 1231 patients $(48 \%) .148(5.76 \%)$ patients had minor complication, and 10 $(0.37 \%)$ patients had major complication. A total of $15(0.58 \%)$ patients underwent intensive care after the procedure. Desaturation was statistically significantly higher in patients with ASA III and above, in procedures take longer than 15 minutes, in patients older than 65 years, and in the presence of chronic obstructive pulmonary disease. The intensive care need after the procedure was also significantly higher in these patient groups.

Conclusion: The incidence of non-operating room anesthesia is increasing steadily. The risks associated with these practices are similar to the anesthesia in the operating room. In order to increase patient safety and reduce complications, it is important to carry out a thorough evaluation before the procedure, to provide proper monitored anesthesia care in appropriate physical conditions, and to establish healthy communication between the teams.

Keywords: Non-operating room anesthesia, sedation, monitorization, complication

\section{GíRiş}

Günümüzde teknolojide giderek artan gelişmeler ameliyathane dışı anestezi uygulamalarında ciddi talep artışına neden olmaktadır. Anestezistler de hastanelerin bu alanda artan taleplerini karşılamakla yükümlüdürler. Ameliyathane dışı anestezi uygulamaları, anestezi ekibi için alıştıkları ortamın dışında bir ortamda çalışma zorunluluğu getirir. Düşük

Atıf yapmak için: Hacıbeyoğlu G, Arıcan Ş, Uzun ST, Tavlan A Ameliyathane Dışı Anestezi Deneyimlerimiz. Selcuk Med J 2019;35(4): 217-224

Açıklama: Yazarların hiçbiri, bu makalede bahsedilen herhangi bir ürün, Aygut veya ilac ile ilgili maddi Gikar iliskisine sahip değildir Arast birincil verilerine tam erişim izni vermek ve derginin talep ettiği takdirde verileri incelemesine izin vermeyi kabul etmektedirler. 
risk grubundaki hastalar kadar yüksek risk grubunda, ciddi komorbiditesi olan hastalara da ameliyathane dışı anestezi uygulamaları yapılmaktadır. Uygulanan işleme bağlı veya anesteziye bağlı ciddi komplikasyonlar da görülebilmektedir. Bu nedenle ameliyathane dışı ortamın hem hasta hem de sağlık çalışanları açısından güvenli hale getirilmesi gerekmektedir. Yapılan işlem sırasında hastanın hareketsiz ve refleks aktivitelerinin baskılanmış olması önemlidir (1). Yeterli monitörizasyon yapılmalı ve ekipman konusunda temel standartlar sağlanmalıdır. Ayrıca tüm hastaların rutin preoperatif değerlendirmeden geçirilerek uygun anestezi planının yapılması ve ekiplerin koopere şekilde çalışması gerekmektedir $(2,3)$.

Bu çalışmada; ameliyathane dışı anestezi uygulamalarındaki hasta profilini, sıklıkla tercih edilen ilaçları, gelişen komplikasyonları ve bu komplikasyonların hastaların fiziksel durumları, ek sistemik hastalıkları ve uygulanan işlemler ile ilişkisini araştırarak deneyimlerimizi sunmayı amaçladık. Çalışma sonuçlarının ameliyathane dışı anestezi uygulamalarında multidisipliner yaklaşıma katkı sağlayacağını düşünüyoruz.

\section{HASTALAR VE YÖNTEM}

Çalışma; Mayıs 2017-Aralık 2017 tarihleri arasında tanı ve tedavi amacıyla ameliyathane dışında sedo-analjezi uygulaması yapılan 18 yaş üstü olguların anestezi kayıtları retrospektif taranarak gerçekleştirildi. Ameliyathane dışı anestezi uygulamalarımız rutin olarak üst gastrointestinal endoskopi (ÜGE) ve kolonoskopi üniteleri, endoskopik retrograd kolanjiopankreotografi (ERCP) ünitesi ve radyoloji ünitesinde yapılmaktadır. Ameliyathane dışı anestezi uyguladığımız tüm birimlerde; kalp atım hızı, non-invaziv arteriyel basınç ve oksijen satürasyon ölçümü yapabilen monitör, end-tidal karbondioksit (CO2) ölçümü yapabilen monitör, oksijen kaynağı, aspiratör ve resüsitasyon için gerekli malzemeler bulunmaktadır. Tüm hastalar işlem öncesi anestezi polikliniğinde preoperatif değerlendirilerek anestezi onamları alındı. İşlem sırasında hastalar monitörize edilereknazalkanülveyayüzmaskesiileoksijendesteği verildi. Sedasyon derecesi Amerikan Anestezistler Derneği (ASA) kılavuzları doğrultusunda minimal, orta derecede veya derin olacak şekilde, yapılan işleme göre ayarlandı. Uygulama bitiminde hastalar işlemin yapıldığı ünitedeki derlenme bölümünde takip edildi. Uyanık, oryante, koopere, vital bulguları stabil, solunum ve kardiyak depresyon riski ortadan kalkan, modifiye Aldrete skoru $\geq 9$ olan hastalar taburcu edildi. Çalışmada; bu prosedür altında sedo-analjezi uygulanan hastaların anestezi kayıtları; yaş, cinsiyet, ASA fiziksel durum skorları, uygulanan işlem, işlemin süresi, sedasyon derecesi, kullanılan ilaçlar, minör komplikasyon (disritmi, desatürasyon, bulantı-kusma, alerjik reaksiyon), major komplikasyon (solunum arresti, kardiyak arrest, ventriküler fibrilasyon gibi ciddi disritmiler), kronik obstrüktif akciğer hastalığı (KOAH) öyküsü ve yoğunbakım ihtiyacı açısından incelendi. Hastaların demografik verileri ve kategorik değişkenleri \% ile ifade edildi. Bu değişkenlerle komplikasyonlar arasındaki ilişki ise ki kare testi ile analiz edildi. İstatistiksel değerlendirmede SPSS 23.0 programı kullanıldı ve $p<0,05$ değeri istatistiksel olarak anlamlı kabul edildi.

\section{BULGULAR}

Mayıs 2017-Aralık 2017 tarihleri arasında 18 yaş üstü toplam 2562 hastaya ameliyathane dışı anestezi uygulaması yapıldı. Hastaların yaş dağılımı 18 - 96 arasında, yaş ortalaması ise $53.08 \pm 16.55$ idi. Hastaların cinsiyetlerine göre yüzde dağılımı Şekil 1 'de verilmiştir.

Olguların 268 (\%10.5)'i ASA I, 1683 (\%65.7)'ü ASA II, 598 (\%23.3)'i ASA III, 13 (\%0.5)'ü ASA IV idi. ASA IV hastaların \%38.4'ü ERCP yapılan olgulardı. Uygulanan işlemlerin ASA fiziksel durum skorlamasına göre dağılımı Tablo 1'de verilmiştir.

En uzun işlem süresi ERCP'de $(28.7 \pm 16.3 \mathrm{dk})$, en kısa işlem süresi ÜGE'de $(10.3 \pm 3.1 \mathrm{dk})$ tespit edildi. Ortalama işlem süresi $16.44 \pm 10.02 \mathrm{dk}$ idi. Tüm işlemler içinde en fazla uygulanan işlem \%31 ile kolonoskopi idi. Uygulanan işlemlerin \% dağılımı Şekil 2'de verilmiştir.

En sık tercih edilen sedatif ajan 2415 (\%94.26) hastada kullanılan midazolam, en sık tercih edilen

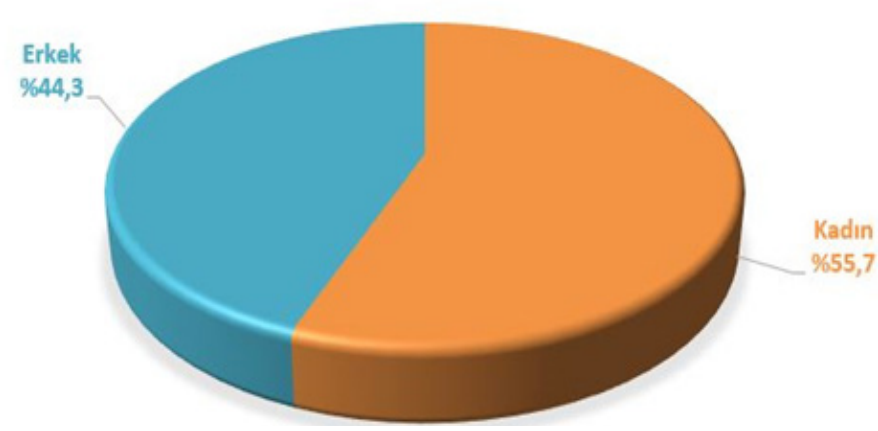

Şekil 1. Hastaların cinsiyetlerine göre yüzde dağılımı 
Table 1. Uygulanan işlemlerin ASA fiziksel durum skorlamasına göre dağılımı

\begin{tabular}{lllll}
\hline & ASA I & ASA II & ASA III & ASA IV \\
$\mathbf{n ~ ( \% )}$ & $\mathbf{n ~ ( \% )}$ & $\mathbf{n}(\%)$ & - \\
\hline ÜGE & $91(34)$ & $301(17,8)$ & $64(10,7)$ & $3(23,1)$ \\
Kolonoskopi & $88(32,8)$ & $556(33,0)$ & $154(25,7)$ & $2(15,3)$ \\
ÜGE +Kolonoskopi & $55(20,5)$ & $332(19,7)$ & $91(15,2)$ & $5(38,5)$ \\
ERCP & $21(7,8)$ & $275(16,3)$ & $201(33,6)$ & - \\
EUS & $8(3)$ & $59(3,5)$ & $18(3,0)$ & $3(23,1)$ \\
Girişimsel Radyoloji & $5(1,9)$ & $120(9,7)$ & $70(11,8)$ & $13(0,5)$ \\
Toplam & $268(10,5)$ & $1683(65,7)$ & $598(23,3)$ & \\
\hline
\end{tabular}

ASA: Amerikan Anestezistler Derneği, ÜGE: Üst gastrointestinal endoskopi, ERCP: Endoskopik retrograd kolanjiopankreotografi, EUS: Endoskopik ultrasonografi

hipnotik ajan 2013 (\%78.57) hastada kullanılan propofol olarak tespit edildi. En sık kullanılan ilaç kombinasyonu 1231 (\%48) hastaya uygulanan midazolam+propofol+fentanil kombinasyonu idi. Kullanılan farklı opioidlerin \% dağılımı Şekil 3'de, hastaların sedasyon derecelerinin \% dağılımı ise Şekil 4'de verilmiştir.

Yapılan işlemler sırasında 148 (\%5.76) hastada minör komplikasyon ile karşılaşıldı. Bunlar 12 (\%0.46) hastada bradikardi, 59 (\%2.30) hastada desatürasyon, 49 (\%1.91) hastada bulantı-kusma ve 28 (\%1.09) hastada alerjik reaksiyon şeklindeydi. Bradikardiye intravenöz atropin, bulantı-kusmaya intravenöz antiemetik, alerjik reaksiyona intravenöz antihistaminik ile müdahale edildi. Desatürasyon gelişen hastalarda ise inspire edilen oksijen akışı artırıldı ve/veya baş geri-çene yukarı (head tilt-chin lift) manevrası uygulandı. Minör komplikasyon gelişen tüm hastalarda uygulanan tedavilere cevap alındı.
$10(\% 0.37)$ hastada major kardiyak ve solunumsal komplikasyon gelişti. 4 (\%0.15) hastada hızlı ventrikül cevaplı atriyal fibrilasyon (HVCAF), $2(\% 0.07)$ hastada ventriküler fibrilasyon (VF) görüldü. HVCAF gelişen hastaların 3'ünde kısa etkili beta blokör ile hız kırıldı, 1 hastada cevap alınamadı ve işlem sonlandırılarak hasta yoğunbakıma devredildi. VF gelişen hastalar defibrile edilerek normal ritme döndürüldü. İki hastanın da işlemi sonlandırılarak hastalar yoğunbakıma devredildi. 4 (\%0.15) hastada solunum arresti gelişti. Bu hastaların üçünde maske ventilasyonu ile spontan solunum geri döndü ve işleme devam edildi.1 hasta ise maske ventilasyonuna rağmen desatürasyonun düzelmemesi ve kardiyak arrest gelişmesi üzerine entübe edilerek resüsite edildi ve yoğunbakıma devredildi. Solunum arresti gelişen 4 hastaya da ERCP işlemi yapılmaktaydı.

Toplam 15 (\%0.58) hasta prosedür sonrası yoğunbakıma devredildi. Bu hastaların da tümüne

Table 1. Uygulanan işlemlerin ASA fiziksel durum skorlamasına göre dağılımı

\begin{tabular}{|c|c|c|c|c|c|c|c|c|}
\hline \multicolumn{5}{|c|}{ Anestezik Ajan } & \multicolumn{4}{|c|}{ Komplikasyon } \\
\hline & $\begin{array}{l}\mathrm{KA} \\
(n: 1)\end{array}$ & $\begin{array}{l}\text { SA } \\
(n: 3)\end{array}$ & $\begin{array}{l}\text { HVCAF } \\
(n: 4)\end{array}$ & $\begin{array}{c}\text { VF } \\
(n: 2)\end{array}$ & $\begin{array}{l}\text { Bradikardi } \\
(n: 12)\end{array}$ & $\begin{array}{l}\text { Desatürasyon } \\
\quad(n: 59)\end{array}$ & $\begin{array}{c}\text { Bulantı Kusma } \\
(n: 49)\end{array}$ & $\begin{array}{l}\text { Alerji } \\
(n: 28)\end{array}$ \\
\hline $\bar{M}$ & - & - & - & - & 2 & - & - & - \\
\hline$P$ & - & - & - & - & - & - & 1 & - \\
\hline$M+P$ & - & - & - & - & - & 4 & 10 & 1 \\
\hline$M+F$ & - & 1 & - & - & - & 2 & 1 & \\
\hline$P+K$ & 1 & - & - & - & - & - & 1 & - \\
\hline$P+R$ & - & - & - & - & - & 2 & - & - \\
\hline$M+P+F$ & - & - & 2 & - & 5 & 30 & 21 & 16 \\
\hline$M+P+K$ & - & - & - & - & - & 1 & - & - \\
\hline$M+P+R$ & - & - & - & - & - & - & 2 & - \\
\hline$M+P+M e$ & - & - & - & - & - & - & 1 & - \\
\hline $\mathrm{K}+\mathrm{P}+\mathrm{F}$ & - & - & - & - & 1 & 1 & - & - \\
\hline$M+P+F+R$ & - & 2 & 2 & 2 & - & 3 & 4 & 2 \\
\hline$M+P+K+F$ & - & - & - & - & 3 & 11 & 6 & 7 \\
\hline$M+P+K+M e$ & - & - & - & - & 2 & 4 & - & - \\
\hline$M+P+K+F+R$ & - & - & - & - & - & 1 & 2 & 2 \\
\hline
\end{tabular}

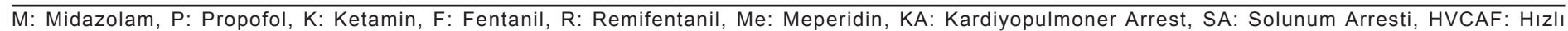
ventrikül cevaplı atriyal fibrilasyon, VF: Ventriküler fibrilasyon 


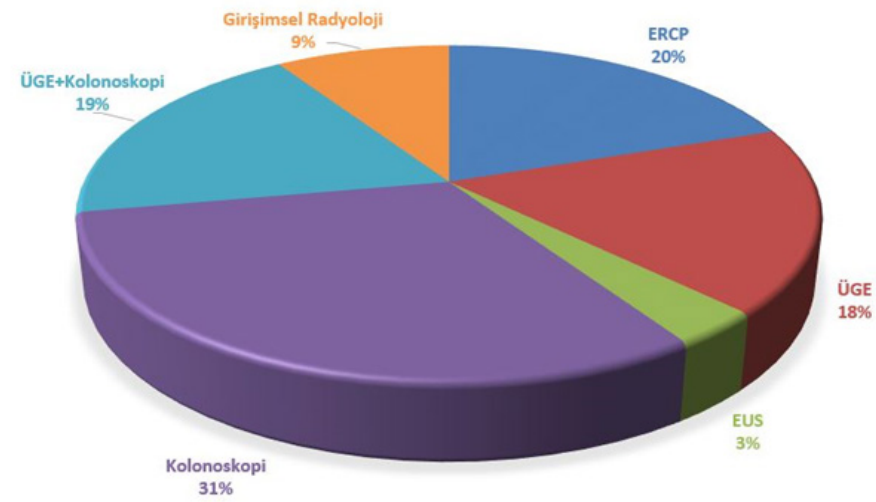

Şekil 2. Uygulanan işlemlerin \% dağılımı

ERCP işlemi yapılmış olup 4'ü işlem esnasında gelişen solunumsal ve kardiyak komplikasyonlar nedeni ile diğerleri ise komorbiditeleri nedeni ile yoğunbakıma devredildi. Komplikasyon gelişen hastalarda kullanılan anestezik ajanların sayısal dağılımı Tablo 2'de verilmiştir.

Gelişen solunumsal komplikasyonlar ve yoğunbakım intiyacının ASA III-IV hastalar, 65 yaş üzeri hastalar ve 15 dakikadan uzun süren işlemlerle olan korelasyonu incelendiğinde desatürasyon ve yoğunbakım ihtiyacının bu hasta grupları ile pozitif koreleolduğutespitedildi. Toplam $181 \mathrm{KOAH}$ hastasının 31 (\%17.1)' inde desatürasyon, 1 (\%0.5)'inde solunum arresti, $8(\% 4.4)$ 'inde yoğunbakım intiyacı tespit edildi. $\mathrm{KOAH}$ hastalarında desatürasyon ve yoğunbakım intiyacı ile pozitif korelasyon tespit edilirken solunum

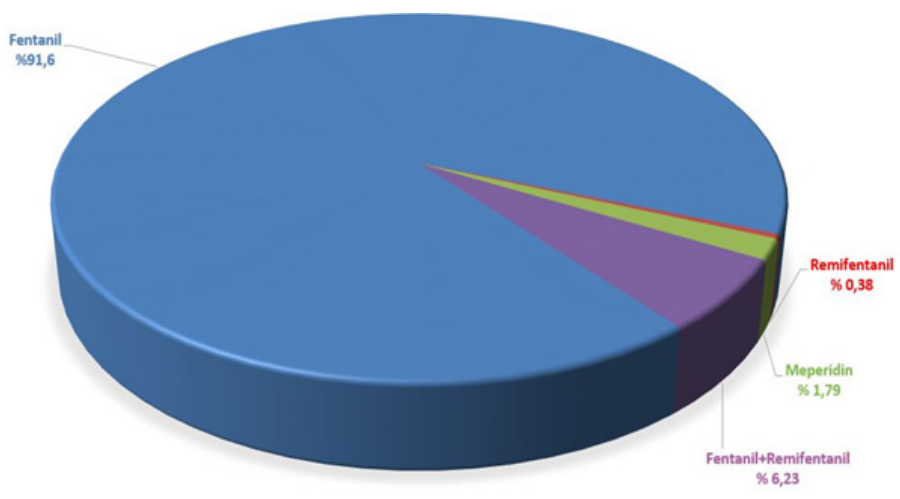

Şekil 3. Kullanılan opioidlerin \% dağılımı

arresti ile korelasyon tespit edilmedi. Solunumsal komplikasyonlar ve yoğunbakım ihtiyacının hastaların kategorik değişkenleri ile korelasyonları Tablo 3'de verilmiştir.

\section{TARTIŞMA}

ASA ameliyathane dışı anestezi uygulamalarını, ameliyathaneden uzak hastaya yakın pratikler olarak tanımlamıştır (4). Bu uygulamaların amacı, hastaların anksiyetelerini ve duydukları ağrıyı hafifleterek invaziv prosedürleri tolere etmelerini sağlamaktır (5). Son yıllarda teknolojide kaydedilen hızlı gelişmenin sağlık sektörüne olan yansıması ameliyathane dışında uygulanan invaziv prosedürleri ve dolayısıyla anestezi uygulamalarına olan ihtiyacı giderek artırmıştır (6). Ancak hizmet verilen lokasyonlar, sıklıkla anestezi

Table 2. Komplikasyon gelişen hastalarda kullanılan anestezik ajanların sayısal dağılımı

\begin{tabular}{|c|c|c|c|c|c|c|c|c|}
\hline \multicolumn{4}{|c|}{ Anestezik Ajan } & \multicolumn{3}{|c|}{ Komplikasyon } & \multirow[b]{2}{*}{$\begin{array}{c}\text { Bulantı Kusma } \\
(\mathrm{n}: 49)\end{array}$} & \multirow[b]{2}{*}{$\begin{array}{l}\text { Alerji } \\
(n: 28)\end{array}$} \\
\hline & $\begin{array}{l}\mathrm{KA} \\
(\mathrm{n}: 1)\end{array}$ & $\begin{array}{l}\text { SA } \\
(n: 3)\end{array}$ & $\begin{array}{l}\text { HVCAF } \\
(n: 4)\end{array}$ & $\begin{array}{l}\text { VF } \\
(n: 2)\end{array}$ & $\begin{array}{l}\text { Bradikardi } \\
(n: 12)\end{array}$ & $\begin{array}{c}\text { Desatürasyon } \\
(n: 59)\end{array}$ & & \\
\hline $\bar{M}$ & - & - & - & - & 2 & - & - & - \\
\hline $\mathrm{P}$ & - & - & - & - & - & - & 1 & - \\
\hline$M+P$ & - & - & - & - & - & 4 & 10 & 1 \\
\hline$M+F$ & - & 1 & - & - & - & 2 & 1 & \\
\hline$P+K$ & 1 & - & - & - & - & - & 1 & - \\
\hline$P+R$ & - & - & - & - & - & 2 & - & - \\
\hline$M+P+F$ & - & - & 2 & - & 5 & 30 & 21 & 16 \\
\hline$M+P+K$ & - & - & - & - & - & 1 & - & - \\
\hline$M+P+R$ & - & - & - & - & - & - & 2 & - \\
\hline$M+P+M e$ & - & - & - & - & - & - & 1 & - \\
\hline $\mathrm{K}+\mathrm{P}+\mathrm{F}$ & - & - & - & - & 1 & 1 & - & - \\
\hline$M+P+F+R$ & - & 2 & 2 & 2 & - & 3 & 4 & 2 \\
\hline$M+P+K+F$ & - & - & - & - & 3 & 11 & 6 & 7 \\
\hline$M+P+K+M e$ & - & - & - & - & 2 & 4 & - & - \\
\hline$M+P+K+F+R$ & - & - & - & - & - & 1 & 2 & 2 \\
\hline
\end{tabular}

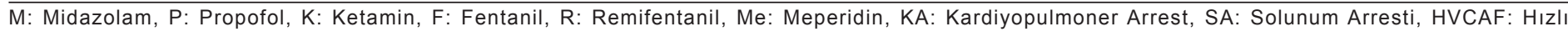
ventrikül cevaplı atriyal fibrilasyon, VF: Ventriküler fibrilasyon 


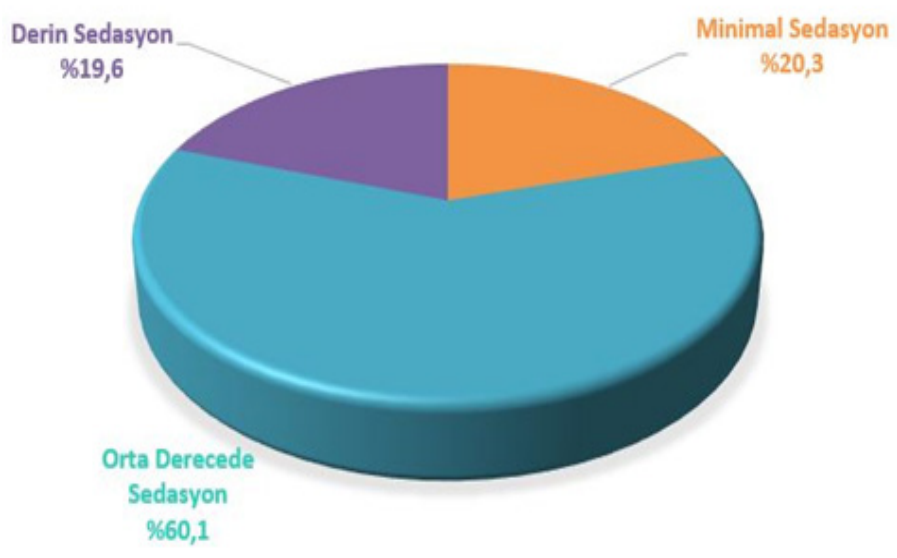

Şekil 4. Sedasyon derecelerinin \% dağılımı

ihtiyacı ve ekipmanı için bir beklenti olmaksızın inşa edilmiş olup anestezi ekibini alışık oldukları düzenin dışında çalışmaya zorlar (7).

Dış anestezi uygulamalarında alınan hastalar sıklıkla işlem günü hastaneye gelen ve haklarında sınırlı bilgi sahibi olunan hastalardır. Bu durum prosedürlerin iptali veya gecikme intimalini artırarak daha çok maliyete neden olabilmektedir (8). Ameliyathane dışında uygulanacak girişimsel işlem ne olursa olsun her hasta genel anestezi alacakmış gibi hazırlanmalıdır, çünkü her an genel anestezi intiyacı doğabilir veya acil bir müdahale için ameliyathaneye transport gerekebilir. Preoperatif değerlendirmede hasta öyküsü ve komorbiditelerinin dikkatli incelenmesi, her hasta ve prosedüre özel ideal bir anestezi uygulamasını şekillendirmeye yardımcı olur (9). Bu nedenle tüm hastalar işlem gününden önce anestezi uzmanı tarafından değerlendirilmelidir. Biz de elektif şartlarda aldığımız hastaları mutlaka ayrıntılı bir preoperatif değerlendirmeden geçirerek, sistemik hastalıkları ile ilgili tedavi düzenlemelerini yaparak, gerekli ise işlem sonrası için yoğunbakım şartlarını hazırlayarak anestezi planımızı yaptık ve hastalara optimum şartlarda sedo-analjezi uyguladık. Yapılan pek çok çalışma hastaların iyi bir preoperatif değerlendirme süreci geçirmesinin potansiyel komplikasyonları ve hastanede kalış sürelerini azalttığını göstermiştir $(10,11)$. Karamnov et al. komplikasyon gelişen hastaların \%5'den fazlasında eksik preoperatif değerlendirmenin sorumlu olduğunu bildirmişlerdir (12). Uygulamalarımızda anestezi kaynaklı major komplikasyon oranlarımızın \%0.37 gibi düşük oranda olmasında preoperatif hazırlık sürecinde izlediğimiz prosedürün katkısı olduğunu düşünüyoruz.

Ameliyathane dışı anestezi uygulamalarında ortaya çıkabilecek komplikasyonlar; gastrik içeriğin aspirasyonu, hipoksi, hipotermi, hipovolemi, şiddetli hipotansiyon, kardiyak komplikasyonlar, anafilaksi, bulantı-kusma ve prosedürle ilişkili komplikasyonlar olarak sayılabilir. Bu komplikasyonların tümü hasta

Table 3. Solunumsal komplikasyon ve yoğunbakım ihtiyacının kategorik değişkenlerle korelasyonu

\begin{tabular}{|c|c|c|c|c|c|c|}
\hline & $\begin{array}{c}\text { Desatürasyon } \\
n(\%)\end{array}$ & $\begin{array}{c}p \\
n(\%)\end{array}$ & $\begin{array}{c}\text { Solunum Arresti } \\
n(\%)\end{array}$ & $p$ & Yoğunbakım & $p$ \\
\hline \multicolumn{7}{|l|}{ ASA I-II } \\
\hline $\begin{array}{l}\mathrm{n}: 1951) \\
\text { ASA III-IV }\end{array}$ & $26(\% 1.3)$ & $<0,001$ & $1(\% 0.05)$ & 0,043 & $2(\% 0.1)$ & $<0,001$ \\
\hline $\begin{array}{l}(\mathrm{n}: 611) \\
\text { İşlem Süresi } \\
<15 \mathrm{dk}\end{array}$ & $33(\% 5.4)$ & & $3(\% 0.49)$ & & $13(\% 2.1)$ & \\
\hline $\begin{array}{l}\text { (n:2036) } \\
\text { İşlem Süresi } \\
\geq 15 \mathrm{dk}\end{array}$ & $29(\% 1.4)$ & $<0,001$ & $1(\% 0.49)$ & 0,029 & $3(\% 0.1)$ & $<0,001$ \\
\hline$(\mathrm{n}: 526)$ & $30(\% 5.7)$ & $3(\% 0.57)$ & $12(\% 2.3)$ & & & \\
\hline $\begin{array}{l}<65 \text { yaş } \\
(\mathrm{n}: 1873)\end{array}$ & $25(\% 1.3)$ & $<0,001$ & $1(\% 0.05)$ & 0,043 & $2(\% 0.1)$ & $<0,001$ \\
\hline $\begin{array}{l}\geq 65 \text { yaş } \\
\text { (n:689) } \\
\text { KOAH Olmavanlar }\end{array}$ & $34(\% 4.9)$ & & $3(\% 0.43)$ & & $13(\% 1.8)$ & \\
\hline $\begin{array}{l}(\mathrm{n}: 2381) \\
\mathrm{KOAH}\end{array}$ & $28(\% 1.1)$ & $<0,001$ & $3(\% 0.12)$ & 0,254 & $7(\% 0.3)$ & $<0,001$ \\
\hline $\begin{array}{l}\text { Olanlar } \\
(\mathrm{n}: 181)\end{array}$ & $31(\% 17.1)$ & & $1(\% 0.5)$ & & $8(\% 4.4)$ & \\
\hline
\end{tabular}


memnuniyetini önemli ölçüde bozarak morbidite ve mortaliteyi artırır (13). Literatürde ameliyathane dışı anestezi uygulamalarında farklı komplikasyon oranları bildirilmiştir. 3583 olguda yapılan bir çalışmada \% 6.2 oranında komplikasyonla karşılaşılmışken 1622 olguda yapılan başka bir çalışmada \% 2.8 oranında komplikasyon saptanmıştır $(14,15)$. \% 0.17 oranında çok daha düşük komplikasyon bildiren çalışmalar da mevcuttur (16). Bizim çalışmamızda ise komplikasyon \% 6.09 olarak tespit edilmiştir. Literatürdeki bu farklı komplikasyon oranlarının analiz edilen hasta sayıları, hasta profilleri ve uygulanan işlemlerdeki farklılıklara bağlı olduğunu düşünüyoruz. Hipoksi, desatürasyon, aspirasyon gibi solunumsal komplikasyonlar en yaygın görülen komplikasyonlardır (17). Cooper et al. 165527 kolonoskopi vakasını retrospektif taradıkları çalışmada en sık görülen komplikasyon mide içeriğinin aspirasyonu olmuştur (16). ÜGE için sedasyon uygulanan 36.000 'den fazla hastanın gözden geçirildiği başka bir çalışmada da yine en sık görülen komplikasyonun solunumsal komplikasyonlar olduğu saptanmıştır. Bu büyük hasta grubunda ölüm veya endotrakeal entübasyon ihtiyacı ise görülmemiştir (18). Bu çalışmalara benzer şekilde bizim çalışmamızda da en sık görülen komplikasyon \%2.3 sıklıkla desatürasyon olarak tespit edildi.

İleri yaş, KOAH, sigara, kalp yetmezliği, yüksek ASA skorları ve obstrüktif uyku apnesi pulmoner komplikasyonlar için risk faktörleridir $(16,19)$. KOAH olan hastalarda hava akımındaki sınırlamalar artmış mortalite ve morbidite ile birliktedir. Bu yüksek riskli hasta grubu anestezi uzmanları tarafından dikkatle değerlendirilmelidir. KOAH'lı hastaların optimizasyonu; mevcut enfeksiyonların tedavisi, sigarayı bırakma, bronkodilatörler ve steroidler kullanarak akciğer fonksiyonlarının iyileştirilmesini içerir. $\quad(20,21) \quad$ Çalışmamızda; solunumsal komplikasyonlar ve yoğunbakım intiyacının ASA III-IV, 65 yaş üzeri, KOAH'lı hastalar ve 15 dakikadan uzun süren işlemlerle pozitif korele olduğu tespit edildi. Preoperatif optimizasyonları yapılmasına rağmen KOAH'lı hastalarda solunumsal komplikasyon ve yoğunbakım ihtiyacındaki pozitif korelasyonun yüksek ASA skorları ve ileri yaşa bağlı olduğunu düşünüyoruz.

Oluşan komplikasyonların büyük kısmı hasta komorbiditeleri ile ilişkili olsa da alışılagelmişin dışında bir ortamda çalışıyor olmak da gözardı edilmemelidir. $\mathrm{Bu}$ nedenle hasta güvenliğinin artırılması ve komplikasyonların azaltıması amacıyla kılavuzların önerdiği standartlar mutlaka sağlanmalıdır. Kalıcı beyin hasarı ve ölüme yol açan ciddi solunum komplikasyonları anestezik bakım ile ilgili davaların büyük kısmını oluşturur (22). Dava dosyalarının \%15'inde pulse oksimetre monitörizasyonu yapılmamıştır ve ASA standartlarına uygun bakım yapıldığında bu komplikasyonların büyük kısmının önlenebileceği öngörülmektedir (23). ASA standartlarına uygun anestezi bakımının en önemli bölümü uygun monitörizasyondur. Kapnograf, apne ve respiratuar depresyonda daha erken bulgu verdiği için obez hastalar, yaşlı bireyler ve KOAH'lı hastalar gibi solunumsal komplikasyonlar açısından yüksek risk taşıyanlarda özellikle önerilmektedir (24). Endoskopik prosedürlerde kapnografinin uygulanması, komplikasyonları azaltmış ve hasta güvenliğini önemli ölçüde artırmıştır (25). Biz de sedo-analjezi uyguladığımız tüm hastalarda kullandığımız kapnograf sayesinde oluşan solunumsal komplikasyonlara zamanında müdahale edebilmekteyiz. Çalışmamızda sadece bir hastada maske ventilasyonuna rağmen desatürasyonun düzelmediği ve kardiyak arrest geliştiği tespit edildi. $\mathrm{Bu}$ hastada aspirasyon ve ek kardiyak problemlerin varlığı arreste neden olmuştur. Diğer desatürasyon ve solunum arresti görülen hastalarda kalıcı hasar gelişmemesini ise doğru uyguladığımız monitörize anestezi bakımı ile sağladığımızı düşünüyoruz.

Ameliyathane dışı anestezi uygulamalarında endoskopik prosedürler önemli bir yer tutmaktadır. Endoskopik ultrason (EUS) ve ERCP, biliyer yollar ve pankreas dahil olmak üzere daha önce sadece cerrahi yolla erişilebilen birçok lezyonun tanı ve tedavisine olanak sağlar (26). Özellikle yaşlı, ciddi komorbiditeleri olan, cerrahi gibi daha invaziv girişimleri tolere edemeyecek hastalar bu prosedürlerin hasta profilini oluşturur. Bu prosedürlerin genellikle lateral dekübit pozisyonda ve derin sedasyon altında uygulanmaları havayoluna erişim açısından anestezi ekiplerinin işini zorlaştırmaktadır (27). Ayrıca şiddetli hipotansiyon, kardiyak disritmiler ve miyokardiyal iskemi gibi kardiyak komplikasyonlar bu hastalarda ölümcül sonuçlara neden olabilir (28). Biz de çalışmamızda ASA III ve IV hastalara en çok ERCP işlemi yapıldığını ayrıca major kardiyopulmoner komplikasyon gelişen ve prosedür sonrası yoğunbakım intiyacı olan tüm hastalara da ERCP yapıldığını tespit ettik. Yoğunbakıma devredilen 15 hastadan 4'ü işlem esnasında gelişen solunumsal ve kardiyak komplikasyonlar nedeni ile diğerleri ise komorbiditeleri nedeni ile yoğunbakıma devredildi.

Girişim yapılacak hastaların anksiyetelerini azaltmak ve prosedüre uygun sedasyon derecesinin ayarlanması komplikasyonların önlenmesi ve işlem 
başarısı açısından önemlidir. Komorbiditelerin varlığı anestezik ilaçların seçimi ve sedasyon derinliğini etkiler $(29,30)$. Hangi ilaçların veya ilaç kombinasyonlarının uygun olduğu ise tartışmalıdır. 36 randomize kontrollü çalışmadan elde edilen verilerin karşılaştırıldığı bir meta-analizde özofagogastroduodenoskopi ve kolonoskopide kullanılan farklı sedasyon rejimleri arasında etkinlik ve güvenilirlikte anlamlı fark bulunmamıştır (31). Fentanil en sık kullanılan opioidlerdendir. Çok düşük dozlarda bile solunum depresyonuna neden olabilir (32). Amnezik etkisi olan midazolam en sık kullanılan sedatiftir ve genellikle propofol ile kombine edilir (33). Propofol ise ideal farmakodinamik ve farmakokinetik profiline ek olarak antiemetik özelliğiyle monitörize anestezi bakımının temel ilacıdır. (34). Yapılan çok sayıda çalışma, propofol anestezisinin daha hızlı geri dönüş sürelerine sahip olduğunu ve kullanımının daha iyi tolere edildiğini göstermektedir (35-37). Türk et al. yaptığı çalışmada 3583 hastanın 3244'ünde propofol kullanıımıştır (14). Biz de uygulamalarımızda hipnotik olarak en çok propofol, sedatif olarak midazolam, opioid olarak da fentanili tercih ettiğimizi belirledik. Bu ilaç tercihlerinde uygulanacak işlem, intiyaç duyulan sedasyon derecesi ve hasta komorbiditelerinin etkili olduğunu düşünüyoruz.

Ameliyathanede olduğu gibi ameliyathane dışı uygulamalarda da anestezi sonrası bakım gözardı edilmemelidir. Çünkü sonlandırılan prosedür ile hastanın ağrılı uyaranının ortadan kalkması derin sedasyon riskini artırır. Sedasyon sonrası bakım mutlaka standart bir şekilde sağlanmalıdır. Önlenebilir solunumsal olaylar derlenme süreçlerinde ortaya çıkar ve bu nedenle tam bir derlenme sağlanana kadar sıkı bir gözlem gereklidir (38). İşlem sonrası tüm hastalar ünitelerin derlenme bölümlerinde takip edilerek güvenli şekilde taburculukları veya ilgili kliniğe transferleri sağlandı. Çalışmamızda; derlenme sürecinde 49 hastada, uygulanan ilaçlar veya prosedüre bağlı bulantı-kusma oluştuğu ve antiemetiklerle tedavi edildiği tespit edildi.

Sonuç olarak ameliyathane dışı anestezi uygulamalarında sedasyon ve hasta izlemi açısından standartların oluşturulması, hasta güvenliğinin sağlanması ve hizmet kalitesinin artırılması için gereklidir. Hastaların işlem öncesi anestezist tarafından değerlendirilmesi, tıbbi durumlarının optimize edilmesi, uygun fiziksel şartlarda iyi bir monitörize anestezi bakımının sağlanması ve ekipler arasında sağlıklı bir iletişimin kurulması komplikasyonları azaltarak hasta memnuniyetini ve işlem başarısını artıracaktır.

Çıkar Çatışması: Çalışmada herhangi bir çıkar çatışması yoktur.

Finansal Çıkar Çatışması: Çalışmada herhangi bir finansal çıkar çatışması yoktur.

Yazışma Adresi: Gülçin Hacıbeyoğlu, Yunus Emre Mahallesi Necmettin Erbakan Üniversitesi Meram Tıp Fakültesi Anesteziyoloji ve Reanimasyon Anabilim Dalı, 42080 Meram/ Konya, Türkiye

Telefon: 05054455498

e-posta:drgulcin81@gmail.com

\section{KAYNAKLAR}

1. Hodgson E. Airway management outside the operating theatre. Saudi J Anaesthesia 2008;2:35-9.

2. Türk Anesteziyoloji ve Reanimasyon Derneği (TARD) Anestezi Uygulama Klavuzları. Ameliyathane Dışı Anestezi Uygulamaları 2015.

3. Sargın M, Sarıtaş TB, Borazan H, et al. ERCP uygulanacak pediatrik hastada anestezi. Selçuk Tıp Derg 2015;31(4):2930.

4. Pomerantz P. CEO report: Away from the O.R. and closer to the patient. American Society of Anesthesiologists Newsletter 2013;77:8-9.

5. Bader AM, Pothier MM. Out-of-operating room procedures: Preprocedure assessment. Anesthesiol Clin 2009;27:121-6.

6. Pino RM. The nature of anesthesia and procedural sedation outside of the operating room. Curr Opin Anaesthesiol 2007;20:347-51.

7. Evron S, Ezri T. Organizational prerequisites for anesthesia outside the operating room. Curr Opin Anaesthesiology 2009;22(4):514-8.

8. Bader AM, Correll DJ. Preoperative assessment and management. In: Sweitzer B, ed. Organizational structure of preoperative evaluation center. Philadelphia: Lippincott, Williams and Wilkins; 2008:420-32.

9. Chang B, Urman RD. Nonoperating room anesthesia: The principles of patient assessment and preparation. Anesthesiol Clin 2016;34:223-40.

10. Cima RR, Brown MJ, Hebl JR, et al. Use of lean and six sigma methodology to improve operating room efficiency in a high-volume tertiary-care academic medical center. J Am Coll Surg 2011;213(1):83-92.

11. Harnett MJ, Correll DJ, Hurwitz S, et al. Improving efficiency and patient satisfaction in a tertiary teaching hospital preoperative clinic. Anesthesiology 2010;112(1):66-72.

12. Karamnov S, Sarkisian N, Grammer R, et al. Analysis of adverse events associated with adult moderate procedural sedation outside the operating room. J Patient Saf 2017;13(3):111-21.

13. Melloni C. Morbidity and mortality related to anesthesia outside the operating room. Minerva Anestesiol 2005;71:32534.

14. Türk HŞ, Aybey F, Ünsal O, et al. Ameliyathane dışı anestezi deneyimlerimiz. Ş.E.E.A.H. Tıp Bülteni 2013;47(1):5-10.

15. İyilikçi L, Çakmak Ş, Ögdül E, et al. Ameliyathane dışı anestezi uygulamalarında deneyimlerimiz. Türk Anest Rean Der Dergisi 2006;34(3):169-76.

16. Cooper GS, Kou TD, Rex DK. Complications following colonoscopy with anesthesia assistance: A population-based 
analysis. JAMA Intern Med 2013;173:551-6.

17. Melloni C. Anesthesia and sedation outside the operating room: How to prevent risk and maintain good quality. Curr Opin Anaesthesiol 2007;20:513-9.

18. Rex DK, Heuss LT, Walker JA, et al. Trained registered nurses/endoscopy teams can administer propofol safely for endoscopy. Gastroenterology 2005;129:1384-91.

19. Smetana GW, Lawrence VA, Cornell JE. Preoperative pulmonary risk stratification for noncardiothoracic surgery: Systematic review for the American College of Physicians. Ann Intern Med 2006;144(8):581-95.

20. Halbert RJ, Natoli JL, Gano A, et al. Global burden of COPD: Systematic review and meta-analysis. Eur Respir J. 2006; 28(3):523-32.

21. Duggappa DR, Rao GV, Kannan S. Anaesthesia for patient with chronic obstructive pulmonary disease. Indian J Anaesth 2015;59(9):574-83.

22. Metzner J, Posner KL, Domino KB. The risk and safety of anesthesia at remote locations: The US closed claims analysis. Curr Opin Anaesthesiology 2009;22(4):502-8.

23. Metzner J, Posner KL, Lam MS, et al. Closed claims' analysis. Best Pract Res Clin Anaesthesiol 2011;25(2):263-76.

24. Waugh JB, Epps CA, Khodneva YA. Capnography enhances surveillance of respiratory events during procedural sedation: A meta-analysis. J Clin Anesth 2011;23:189-96.

25. Saunders R, Erslon M, Vargo J. Modeling the costs and benefits of capnography monitoring during procedural sedation for gastrointestinal endoscopy. Endosc Int Open 2016;4(3):E340-51.

26. DeVilliers WJ. Anesthesiology and gastroenterology. Anesthesiol Clin North America 2009;27:57-70.

27. Robbertze R, Posner KL, Domino KB. Closed claims review of anesthesia for procedures outside the operating room. Curr Opin Anaesthesiol 2006;19: 436-42.
28. Amornyotin S. Sedatio-related complications in gastrointestinal endoscopy. World J Gastrointest Endosc 2013;5:527-33.

29. Evron S, Ezri T. Organizational prerequisites for anesthesia outside the operating room. Curr Opin Anaesthesiol 2009;22:514-8.

30. Souter KJ, Davies JM. Diversification and specialization in anesthesia outside the operating room. Curr Opin Anaesthesiol 2012;25:450-2.

31. McQuaid KR, Laine L. A systematic review and meta-analysis of randomized, controlled trials of moderate sedation for routine endoscopic procedures. Gastrointest Endosc 2008; 67:910-23.

32. Gesztesi Z, Rego MM, White PF. The comparative effectiveness of fentanyl and its newer analogs during extracorporeal shock wave lithotripsy under monitored anesthesia care. Anesth Analg 2000;90:567-70.

33. Ghisi D, Fanelli A, Tosi $M$, et al. Monitored anesthesia care. Minerva Anestesiol 2005;71: 533-8 .

34. Casati A, Fanelli G, Casaletti E, et al. Clinical assessment of target-controlled infusion of propofol during monitored anesthesia care. Can J Anaesth 1999;46:235-9.

35. Poulos JE, Kalogerinis PT, Caudle JN. Propofol compared with combination propofol or midazolam/fentanyl for endoscopy in a community setting. AANA J 2013;8:31-6.

36. Wang D, Chen C, Chen J, et al. The use of propofol as a sedative agent in gastrointestinal endoscopy: A metaanalysis. PLoS One 2013;8(1):e53311.

37. Horiuchi A, Nakayama Y, Kajiyama M, et al. Safety and effectiveness of propofol sedation during and after outpatient colonoscopy. World J Gastroenterol 2012;18:3420-5.

38. Amornyotin S. Sedatio-related complications in gastrointestinal endoscopy. World J Gastrointest Endosc 2013;5:527-33. 